\title{
A Fluorescence Study on Surface Properties of Cationic Gemini Surfactant with Some Special Alcohols
}

\author{
RIYAJ MOHAMMAD \\ Department of Chemistry, Gandhi Faiz-E-Aam College (Affiliated to M.J.P. Rohilkhand University, Bareilly), \\ Shahjahanpur-242001, Uttar Pradesh, India \\ E-mail: riyaz138@gmail.com \\ Received: 7 November 2020 \\ Accepted: 21 December $2020 \quad$ Published: 31 December 2020
}

\begin{abstract}
Alcohols are very important additives and played a measure role as co-surfactants in various industrial and research applications. While, Gemini surfactants are mainly used as effective emulsifiers, antifoaming agents, bactericidal agents, coating agents and corrosion inhibitors etc. Therefore, it is important to study about the variations in alkanol concentrations which affects the aggregation number and other related parameters. Surface properties of gemini surfactant butanediyl-1,4-bis(dimethyldodecylammonium bromide) (12-4-12) has been studied by using fluorescence method. This method has been used to calculate the aggregation number $\left(N_{a g g}\right)$ and the other related parameters like dielectric constant (D), Stern Volmer binding constant $\left(K_{S V}\right)$ of mixed system. This method is also very important for the calculation of the micropolarity of the mixed system (gemini/alcohol). The micropolarity has been obtained with the help of the ratio of intensity of peaks $\left(I_{1} / I_{3}\right)$ of the pyrene fluorescence emission spectrum. Cetylpridinium chloride and pyrene were used as quencher and probe, respectively.
\end{abstract}

Keywords: Gemini surfactant, special alcohols, aggregation number, micropolarity

Copyright : This is an open access article distributed under the terms of the CC-BY-NC-SA(Creative Commons Attribution-NonCommercial-ShareAlike 4.0 International License) which permits unrestricted use, distribution, and reproduction in any medium, for non-commercial purposes, provided the original work of the author(s) is properly cited.

\section{INTRODUCTION}

Surfactants or detergents are the agents which have lyophilic and lyophobic parts in a molecule. These molecules show very interesting properties of both adsorptions on surface as well as interfaces at very low concentrations. The surface tension is being reduced when surfactants are used in low concentration.

The lyophilic part of the surfactants is soluble in water while lyophobic part is water insoluble. When water is used as a solvent then these parts are called hydrophilic and hydrophobic. The charge bearing portion is called hydrophilic and long chain (tail) is called hydrophobic. There are many examples of the conventional surfactants on which the surface properties have been studied very well. The surfactants have long carbon chain that may be linear or branched and the charge bearing part may be ionic. The hydrophilic part of the surfactants interacts strongly with the polar part of the water molecule.

Surfactants possess many applications both in everyday life as well as in the industrial field. Gemini surfactants showed more efficient properties as compared to conventional surfactants. These type of surfactants have two hydrophilic and two hydrophobic parts and their hydrophilic parts are being connected with a spacer. The examples include hexnediyl-1,6-bis(dimethylcetylammoniumbromide) (16-6-16), pentanediyl-1,5-bis (dimethylcetylammoniumbromide) (16-5-16), etc. (Ionescu \& Fung, 1981; Warnheim \& Jonsson, 1998; Jonstronger et al., 1990; Gharibi et al., 1992; Sjober et al., 1993).

Gemini or dimeric surfactants have been first prepared by Mitsui Okahara and his colleagues (Okahara et al., 1988). These surfactants show more efficient wetting properties (Rosen, 1993) 
than conventional surfactants and possess very low critical micelle concentration $(C M C)$. They show specific rheological and specific aggregation properties (Zana \& Talmon, 1993; Frindi et al., 1994; Alami et al., 1993; Talmon \& Binks, 1999).

A schematic presentation of Gemini surfactant as shown in Figure 1 contains the polar or ionic parts are connected through spacer. Due to excellent surface activity, Gemini surfactants possess many applications in various fields. They are mainly used in foaming, spreading aids and cleaning processes etc. These surfactants are used in gene therapy as well as bio-imaging because of their ability to interact with DNA (Ahmed et al., 2016). Gold, silver and gold-silver alloy nanoparticles can be prepared using Gemini surfactants with the help of seed mediated method (Tiwari et al., 2015). The purpose of selecting the present alcohols is to find out the effect of various special alcohols as additives in the Gemini surfactants, as these alcohols are expected to show advanced properties when compared to simple linear chain alcohols. Also, to the best of our knowledge, this is for the first time that the aggregation number of cationic Gemini surfactant in presence of special alcohols is reported. Mainly alcohols are used as co-surfactants with surfactants + oil systems to create micro-emulsion. The alcohol played very important role in microemulsion, as it decreases the binding modulus (Binks et al., 1989; Strey \& Jonstromer, 1992) and increases the fluidity of the system (Lianos et al., 1982).

\section{METHODOLOGY}

The special alcohols 1,2-butanediol $(\geq 98.2 \%$, Sigma-Aldrich, Germany), 2-methyl-1-butanol ( $\geq 99.3 \%$, Sigma-Aldrich, Germany), 2-ethyl-1butanol ( $\geq 98.2 \%$, Sigma-Aldrich, Germany), and 2-butene-1,4-diol $\quad(\geq 95.5 \%, \quad$ Sigma-Aldrich, Germany) were used as received. These branched chain alcohols are very much effective in the formation of mixed micelle.
The chemical structures of special alcohols are given below.

$$
\begin{gathered}
\text { OH } \\
\mathrm{CH}_{3}-\mathrm{CH}_{2}-\stackrel{\mathrm{CH}}{1}-\mathrm{CH}_{2}-\mathrm{OH} \\
\text { 1,2-butandiol } \\
\mathrm{CH}_{3} \\
\mathrm{C}_{2} \mathrm{H}_{5}-\mathrm{CH}-\mathrm{CH}_{2}-\mathrm{OH} \\
\text { 2-methyl-1-butanol } \\
\mathrm{C}_{2} \mathrm{H}_{5} \\
\mathrm{C}_{2} \mathrm{H}_{5}-\mathrm{CH}-\mathrm{CH}_{2}-\mathrm{OH} \\
\text { 2-ethyl-1-butanol } \\
\mathrm{HO}-\mathrm{CH}_{2}-\mathrm{CH}=\mathrm{CH}-\mathrm{CH}_{2}-\mathrm{OH} \\
\text { 2-butene-1,4-diol }
\end{gathered}
$$

The dimeric surfactant has been prepared by using 1,4-dibromobutane $(\geq 98.3 \%$, Merck, Germany), with $N, N$-dimethyldodecylamine ( $\geq 95.5 \%$, Fluka, Germany) in dry alcohol at $80.15{ }^{\circ} \mathrm{C}$ for $48 \mathrm{~h}$ with stirring continuously. TLC technique was used to record the progress of the reaction. Recrystallization process has been used to remove solvent. The obtained values were in agreement with the reported literature data (Bhattachrya et al., 1996). Hitachi F-2500 fluorescence spectrometer has been used to record the spectra.

\section{RESULTS AND DISCUSSION}

The calculated values of mean aggregation number give an idea of structure and dimensions of the micelles formed by surfactant in the solution. The mean aggregation number is the amount of surfactant molecules that occupy together to form a spherical structure called micelle. Mainly their shape looks like a bubble. Force of attraction in the

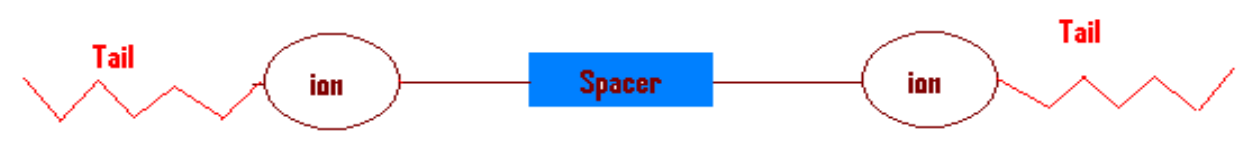

Figure 1. Schematic representation of Gemini surfactant 
micellar solution depends on hydrocarbon chain of the monomer. In view from the geometric considerations, the aggregation number $\left(N_{a g g}\right)$ increased rapidly in aqueous media if the length of the hydrophobic group $\left(l_{c}\right)$ of the surfactant molecule is increased, while it decreased when there is an increase in the inter-section area $\left(a_{0}\right)$ of the lyophilic group.

For calculating the micellar aggregation numbers $\left(N_{a g g}\right)$ of pure and mixed system, Fluorescence quenching is the best method. It is more competent method. All the spectra were recorded at the room temperature i.e., $298.15 \mathrm{~K} . \mathrm{N}_{2}$ stream was used to evaporate the solvent. By keeping pyrene concentration constant at $2 \times 10^{-6}$ mol. $\mathrm{L}^{-1}$, the surfactant solution has been added into the volumetric flask.

The Micellar aggregation numbers $\left(N_{\text {agg }}\right)$ is calculated using Eq. (1) (Turro \& Yekta, 1978).

$$
\ln I_{0}=\ln I_{Q}+\frac{N_{a g g}[Q]}{[S]-c m c}
$$

The $[Q]$ and $[S]$ represent the concentrations of quencher and total surfactant concentration respectively, while $I_{0}$ represent the intensity of fluorescence when quencher is absent and $I_{Q}$ represents the intensity of fluorescence when quencher is present.

Spectra have been recorded at different mole fractions of alcohols (data is given in the Table 1). High values of $N_{a g g}$ are obtained for mixtures as compared to pure solution (when no additive is added). The obtained data are in good agreement with the literature (Mohammad, 2019). The high concentration of the alcohols will decrease the repulsion among head groups so the compact micelles with higher aggregation number will be formed.

Table: 1 Aggregation number and other related parameter calculated by fluorescence measurements

\begin{tabular}{|c|c|c|c|c|c|c|}
\hline$\alpha_{1}$ & $N_{a g g}$ & $N_{\text {gem }}$ & $N_{\text {alcohol }}$ & $\begin{array}{c}K_{S V} / 10^{4} \\
\left(\mathrm{~mol}^{-1} \mathrm{dm}^{3}\right)\end{array}$ & $I_{1} / I_{3}$ & $D$ \\
\hline \multicolumn{7}{|c|}{ System: 1,2-butandiol /12-4-12 } \\
\hline 0.00 & 35 & 35 & 0 & 5.9 & 1.86 & 68 \\
\hline 0.20 & 111 & 86 & 25 & 4.8 & 1.70 & 55 \\
\hline 0.40 & 125 & 75 & 50 & 3.1 & 1.48 & 38 \\
\hline 0.60 & 164 & 65 & 99 & 4.7 & 1.87 & 69 \\
\hline 0.80 & 292 & 81 & 211 & 3.9 & 1.99 & 78 \\
\hline \multicolumn{7}{|c|}{ System: 2-methyl-1-butanol/12-4-12 } \\
\hline 0.20 & 59 & 47 & 12 & 9.2 & 1.50 & 40 \\
\hline 0.40 & 88 & 53 & 35 & 16.6 & 1.85 & 67 \\
\hline 0.60 & 87 & 35 & 52 & 5.6 & 1.72 & 57 \\
\hline 0.80 & 140 & 28 & 112 & 10.8 & 2.96 & 156 \\
\hline \multicolumn{7}{|c|}{ System: 2-ethyl-1-butanol /12-4-12 } \\
\hline 0.20 & 48 & 38 & 10 & 5.3 & 1.64 & 50 \\
\hline 0.40 & 54 & 34 & 20 & 3.5 & 1.84 & 66 \\
\hline 0.60 & 76 & 31 & 45 & 5.9 & 1.86 & 68 \\
\hline 0.80 & 109 & 22 & 87 & 8.5 & 2.34 & 107 \\
\hline \multicolumn{7}{|c|}{ System: 2-butene-1,4-diol/12-4-12 } \\
\hline 0.20 & 49 & 39 & 10 & 5.6 & 1.82 & 65 \\
\hline 0.40 & 52 & 31 & 21 & 4.4 & 1.55 & 43 \\
\hline 0.60 & 65 & 26 & 39 & 7.1 & 1.73 & 58 \\
\hline 0.80 & 81 & 16 & 65 & 13.4 & 1.95 & 75 \\
\hline
\end{tabular}

$\alpha_{1}=$ concentration of alcohols. 
The intensity ratio of vibronic peaks, first $\left(I_{1}\right)$ and third $\left(I_{3}\right)$, represents the index of micropolarity of the system in the presence of surfactant i.e. it provides a view on the microenvironment of the micelle. The smaller value of this ratio $(<1)$ represents that pyrene have nonpolar surrounding, whereas greater value $(>1)$ represents that the pyrene is having polar surrounding (Kalyanasundram \& Thomas, 1977). Eq. (2) was used for calculating the apparent dielectric constant (Maeda, 1995).

$$
\frac{I_{1}}{I_{3}}=1.00461+0.01253 D
$$

The local polarity is measured by calculating the values of $D$ from Eq. (2) where the probe is present. If all the molecules are present into the regions of micelle it means that the size of the probe is large. The obtained $\mathrm{D}$ values in Table 1 are the mean values. This is due the complementary effect, which is created by the separation of the ionic head groups of Geminis. The dielectric constant on polar surfaces in water is reduced when the surface electrical potencia is increased; this is due to the orientation of water molecules by the electric field (Ferchmin, 1995; Lamm \& Pack, 1997). The intercalation of alcohol species between the charges bearing part of the surfactant must increase the value of $D$ with respect to that in the pure surfactant micelles.

Stern-Volmer binding constant, $\left(K_{S V}\right)$ (RohatgiMukherjee, 1992) has also been calculated by applying Eq. (3).

$$
\frac{I_{1}}{I_{3}}=1+K_{S V}[Q]
$$

Here $K_{S V}$ is referred as the ratio of the bimolecular quenching constant to the unimolecular decay constant. If one got the higher value of $K_{S V}$ values, it means that the pyrene having longer lifetime in micellar solutions and quenching is more efficient.

\section{CONCLUSION}

As the concentration of alcohols increase the values of $N_{\text {gem }}$ and $N_{\text {alcohol }}$ also increases. This indicates the strong synergism between Gemini surfactant and additives (alcohols). When micelles are formed from more than one chemical species, then there is a formation of mixed micelle. Mixed micelles have very important applications in technical, pharmaceutical, and biological fields because they work better than pure micelles (Holland \& Rubingh, 1992). The aim of this study is to find the effect of different alcohols on Gemini surfactant, furthermore they can be used again for drug encapsulation and in delivery. Also alcohols are very good co-surfactants and they can be used in micro-emulsion formulation (Lianos et al., 1984) There are very few studies using amines as co-surfactants so they are also potential candidates for such formulation (Wormuth \& Kaler, 1987).

\section{REFERENCES}

Ahmed, T., Kamel, A.O. \& Wetting, S.D. (2016). Interactions between DNA and gemini surfactants: Impact on gene therapy: part I. Nanomedicine, 11: 289-306.

Alami, E., Levy, R., \& Skoulious, A. (1993). Alkanediyl- $\alpha, \omega$-bis(dimethylalkylammoniumbromide) surfactants. 2. Structure of the lyotropic mesophases in the presence of water. Langmuir, 9: 940-944.

Binks, B.P., Meunier, J., Abillon, O. \& Langevin, D. (1989). Measurement of film rigidity and interfacial tensions in several ionic surfactant-oil-water microemulsion systems. Langmuir, 5: 415-421.

De, S., Aswal, V.K., Goyal, P.S. \& Bhattacharya, S. (1996). Role of spacer chain length in dimeric micellar organization. Small angle neutron scattering and fluorescence studies. Journal of Physical Chemistry, 100: 11664-11671.

Ferchmin, D. (1995). Phase diagram of hydration shells in ionic solutions. Journal of Physical Chemistry, 99: 5658-5665.

Frindi, M., Michels, M., Levy, B. \& Zana, R. (1994). Alkanediyl- $\alpha, \omega$-bis(dimethylalkylammoniumbromide) surfactants. 4. Ultrasonic absorption studies of amphiphile exchange between micelles and bulk phase in aqueous micellar solutions. Langmuir, 10: 1140-1145.

Gharibi, H., Palepu, R., Bloor, D.M.D., May, G. \& WynJones, E. (1992). Micellization of cationic surfactants in ethylene glycol: A Electrochemical studies. Langmuir, 8: 782-787. 
Holland, P.M. \& Rubingh, D.N. (eds.). (1992). Mixed surfactant systems. ACS Symposium Series, 501, American Chemical Society, Washington, DC, pp 230 .

Ionescu, L.G. \& Fung D.S. (1981). Micelles formation of acylcarnitine chlorides in presence of ethylene glycol. Journal of Chemical Society, Faraday Transactions, 77: 2907-2912.

Jonstronger, M., Sjober, M. \& Warnheim, T. (1990). Aggregation and solvent interaction in nonionic surfactant systems with formamide. Journal of Physical Chemistry, 94: 7549-7555.

Kalyanasundram, K. \& Thomas, J. K. (1977). Effect of environment on vibronic band intensities in pyrene monomer fluorescence and their application in studies of micellar systems. Journal of American Chemical Society, 99: 2039-2044.

Lamm, G. \& Pack, G.R. (1997). Calculation of dielectric constants near polyelectrolytes in solution. Journal of Physical Chemistry B, 101: 959-965.

Lianos, P., Lang, J., Strazielle, C. \& Zana, R. (1982). Fluorescence probe study of oil-in-water microemulsions. 1. Effect of pentanol and dodecane or toluene on some properties of sodium dodecyl sulfate micelles. Journal of Physical Chemistry, 86: 1019-1025.

Lianos, P., Lang, J., Sturm, J. \& Zana, R. (1984). Fluorescence-probe study of oil-in-water microemulsions. 3. Further investigations involving other surfactants and oil mixtures. Journal of Physical Chemistry, 88: 819-822.

Maeda, H. (1995). Thermodynamic analysis of the stability of ionic/nonionic mixed micelles. Journal of Colloid and Interface Science, 172: 98-105.

Mohammad, R. (2019). Flourescence study of cationic Gemini surfactant 1,4-bis(dimethylcetylammonium bromide) in the presence of alcohols. Journal of Emerging Technology and Innovative Research, 6: 999-1007.
Okahara, M., Masuyama, A., Sumida, Y. \& Zhu, Y-P. (1988). Surface active properties of new types of amphipathic compounds with two hydrophilic ionic groups and two lyophilic alkyl chains. Journal of Japan Oil Chemists Society, 37: 746-748.

Rohatgi-Mukherjee, K.K. (1992). Fundamentals of Photochemistry; Wiley Eastern, New Delhi.

Rosen, M.J. (1993). Geminis: A New Generation of Surfactants. Chemtech, 23:30-33.

Sjober, M., Silveston, R. \& Kronberg, B. (1993). A thermodynamic study of solvophobic effect in formamide solutions of nonopolar molecules. Langmuir, 9: 973-979.

Strey, R. \& Jonstromer, M. (1992). Role of mediumchain alcohols in interfacial films of nonionic microemulsions. Journal of Physical Chemistry, 96: 4537-4542.

Talmon, Y., Binks B.P. (Ed.). (1999). Modern Characterization Methods of Surfactant Systems. Dekker, New York, pp 147-178.

Tiwari, A.K., Gangopadhyay, S., Chang, C.H., Pande, S., \& Saha, S.K. (2015). Study on metal nanoparticles synthesis and orientation of Gemini surfactant molecules used as stabilizer. Journal of Colloid and Interface Science, 445: 76-83.

Turro, N.J. \& Yekta, A. (1978). Luminescent Probes for detergent solutions. An easy method to determine the Mean Aggregation Number of Micelles. Journal of American Chemical Society, 100: 5951-5952.

Warnheim, T. \& Jonsson, A. (1998). In the presence of polar solvents Phase diagram of alkyltrimethyl ammonium surfactants. Journal of Colloid and Interface Science, 125: 627-633.

Wormuth, K.R. \& Kaler, E.W. (1987). Amines as microemulsion co-surfactant. Journal of Physical Chemistry, 91: 611-617.

Zana, R. \& Talmon, Y. (1993). Dependence of Aggregation Morphology on Structure of Dimeric Surfactants. Nature, 362: 228-230. 